\title{
EQUIPMENT FOR PREPARATION OF PIPE ENDS TO WELDING OF POSITION BUTT JOINTS OF PIPELINE
}

\author{
L.M. LOBANOV ${ }^{1}$, N.M. MAKHLIN ${ }^{2}$, V.K. SMOLYAKOV ${ }^{2}$, V.E. VODOLAZSKY ${ }^{2}$, \\ V.E. POPOV ${ }^{2}$ and A.A. SVIRIDENKO ${ }^{3}$ \\ ${ }^{1}$ E.O. Paton Electric Welding Institute, NASU \\ 11 Bozhenko Str., 03680, Kiev, Ukraine. E-mail: office@paton.kiev.ua \\ ${ }^{2} \mathrm{SE} \ll$ Research Engineering Center of Welding and Control \\ in Power Engineering of E.O. Paton Electric Welding Institute» \\ 11 Bozhenko Str., 03680, Kiev, Ukraine. E-mail: electro@paton.kiev.ua \\ ${ }^{3}$ Company CHEZARA \\ 25 Odintsov Str., 14030, Chernigov, Ukraine. E-mail: mial@chezara.com
}

\begin{abstract}
The results are given on developments of the PWI and its special sub-divisions in creation of domestic specimens of current equipment for preparation to welding of ends and edges of position butts of 14-159 mm diameter pipelines from austenite and pearlite class steels and high alloys in assembly, repair and modernization of power engineering objects, including power generating units of nuclear and heat electric plants, in chemical and power machine building, at enterprises of oil-and-gas complex and other branches of industry. Studied are the peculiarities of design of developed end facers for treatment of 14-76 mm diameter pipes with wall thickness up to $7 \mathrm{~mm}$ and pipe cutters for treatment of $\mathrm{V}$ - and U-groove edges of position butts in pipes of 76-159 $\mathrm{mm}$ diameter and up to $12 \mathrm{~mm}$ wall thickness and main constituents of this equipment. It is shown that developed domestic equipment, in comparison with foreign analogues, has a series of significant advantages allowing increasing total efficiency of machining and reducing time of personal staying in zone of influence of harmful environment factors. 26 Ref., 5 Tables, 6 Figures.
\end{abstract}

Key $\boldsymbol{y} \boldsymbol{w} \boldsymbol{O} \boldsymbol{d} \boldsymbol{s}:$ nuclear power engineering, pipeline position butts, automatic orbital welding, machining, pneumatic drives, end facers, pipe cutters, supports, cutting tools

In the most cases, pipelines of power engineering objects, oil-and-gas complex and other branches of economy are the base elements of technological circuits which require performance of significant amount of welded joints. For example, assembly of one power generating unit of nuclear power plant (NPP) with water-moderated type reactor requires performance of not less than 120,000 pipeline welded joints, as a rule, in form of position butts. Functions, performed by pipelines of NPP power generating units, and their effect on life, safety and nuclear safety, complexity of their operation conditions provide for high requirements to quality, service properties and corrosion resistance of welded joints of such pipelines [1-5]. At that, the pipelines are subjected to effect (in the most cases simultaneous) of high temperatures, increased pressure, corrosion and radiation activity of heat carrier and other media, tightness in places of welding performance and limited access to this places. Majority of the similar requirements exist for pipelines in objects in other branches of economy.
Multiple researches and longstanding practice proved that fulfillment of these requirements is only possible under condition of providing of high quality in preparation for welding of pipe ends or edges for pipeline position butts by means of their machining with the help of special metal cutting equipment [3-8]. Earlier Ukraine did not have development and commercial production of such equipment. Therefore, up to the moment organizations and enterprises of nuclear power engineering and other branches of Ukrainian economy should use equipment of similar designation which comes into Ukraine only by means of import and can only partially fulfill Ukrainian consumers according to its properties. Besides, absence of domestic current equipment for preparation of pipeline position butts for welding is one of the main factors preventing wide-scale automation of welding operations at assembly, repair and updating of power engineering objects and other braches of Ukrainian economy.

Taking into account circumstances mentioned above, development of domestic technologies as well as creation and mastering of domestic industrial production of state-of-the-art equipment for preparation of pipeline position butts for welding is very relevant task. 
Aim of the present work lies in studying some important peculiarities of the processes of machining for welding of pipe ends and edges of pipeline position butts and equipment for realizing these processes as well as representation of results of investigations, pilot-technical and pilot-design works, carried in 2013-2014 at the PWI together with REC WCPE in the following directions:

- determining and optimizing the requirements to processes on preparation for welding of position butts in NPP pipelines of $14-219 \mathrm{~mm}$ diameter and defining the optimum parameters and modes of machining of pipe ends of up to $4 \mathrm{~mm}$ wall thickness and $\mathrm{V}$ - and $\mathrm{U}$-groove edges of welds in pipes with up to $12 \mathrm{~mm}$ wall thickness;

- development of construction solutions for equipment used in preparation for welding of position butts of 14-159 $\mathrm{mm}$ diameter pipelines and drawing up of technical documents for pilot samples of corresponding domestic equipment, arrangement of their production, manufacture, setting, finishing, testing and pilot-industrial inspection of these pilot specomens.

Investigations of peculiarities of processes on preparation for welding of position butts of 14-219 mm diameter NPP pipelines. Investigations and technological works covered the study of effect of accuracy of pipeline part edges preparation on welded joint quality. Structural components of such parts correspond to PN AE G-7009-089 and OST 24.125.02-89 requirements. Besides, ranges of optimum modes of treatment by cutting were determined, which should provide correspondence of edge preparation and surfaces of pipeline parts to the requirements of normative documents acting in the field of nuclear power engineering of Ukraine.

Specimens of pipeline parts from 08Kh18N10T steel of 18, 38 and $57 \mathrm{~mm}$ nominal diameters and $2.5,3.5$ and $4 \mathrm{~mm}$ nominal wall thickness, respectively, as well as from steel 20 of 108,159 and $219 \mathrm{~mm}$ nominal diameters and 5, 6.5 and $12 \mathrm{~mm}$ nominal wall thickness, respectively, were used for investigations. Edges of specimens of pipeline parts used for investigations were treated with the help of versatile turn-mill machine 1M61 and milling machine 6R82Sh.

Ends of specimens of pipeline parts from steel 08Kh18N10T were treated in such a way, applicable to S-39 welded joint, as to simulate deviation of specimen plane end from plane normal to longitudinal pipe axis. These are the conditions of non-regular gap and deviation of internal diameters of pipeline part, subjected to welding, from reference values, i.e. conditions of joining of parts with different wall thickness.
Table 1. Linear and angular dimensions of specimens of pipeline parts from 08Kh18N10T steel for simulation of non-regular gap

\begin{tabular}{||c|c|c|c||}
\hline \multirow{2}{*}{$\begin{array}{c}\text { Nominal } \\
\text { diameter } \times \text { pipe thickness } \\
(D \times S), \mathrm{mm}\end{array}$} & \multicolumn{3}{|c|}{ The largest value of non-regular gap $\delta, \mathrm{mm}$} \\
\cline { 2 - 4 } & 0.3 & 0.5 & 0.7 \\
\cline { 2 - 4 } & \multicolumn{3}{|c|}{$\begin{array}{r}\text { Angle of deviation of line normal to pipe } \\
\text { longitudinal axis } \alpha, \text { angle deg }\end{array}$} \\
\hline $18 \times 2.5$ & 1.23 & 1.72 & 2.88 \\
\hline $38 \times 3.5$ & 0.55 & 0.92 & 1.29 \\
\hline $57 \times 4.0$ & 0.36 & 0.60 & 0.84 \\
\hline
\end{tabular}

Treatment of ends in specimens of pipeline parts from 08Kh18N10T steel for non-regular gap conditions in performance of S-39 type welded joint was carried out in accordance with Table 1.

Treatment of ends in specimens of pipeline parts from 08Kh18N10T steel for conditions of joining the parts with different wall thickness in performance of S-39 type welded joint was carried out in accordance with Table 2 .

Treatment of groove edges in specimens of pipeline part from steel 20 for simulation of deviations of linear and angular dimensions, regulated by PN AE G-7-009-089 and OST 24.125.0289 for S-42 type welded joint was performed in accordance with Figure 1 and Table 3. Skewness of bevel angles in samples of pipeline parts from steel 20 for simulation of deviations from reference values for pipes with nominal sizes $108 \times$ $\times 5,159 \times 6.5,219 \times 12 \mathrm{~mm}$ made 4,8 and 12 angle degree.

Control of linear and angular dimensions in process of treatment of specimens of pipeline parts from 08Kh18N10T steel and steel 20 was carried out with the help of standard measurement instrumentation, in particular, calipers ShTs-P-160 and ShTs-P-250 on GOST 166 (the largest measurement error \pm 0.07 and $0.08 \mathrm{~mm}$, respectively), indicator pipe wall thickness gauges S-10A and S-25 on GOST 11358 (the largest measurement error \pm 0.02 and $0.10 \mathrm{~mm}$, respectively), angle gauge with vernier UT mod. 127 of $0-180$ angle degree measurement range on GOST 5378 and the largest measurement error \pm 2 angle min, and set of probes No.3 [9].

Table 2. Linear dimensions of specimens of pipeline parts from 08Kh18N10T steel for simulation of joining conditions of pipe parts of different wall thickness

\begin{tabular}{||c|c|c|c||}
\hline \hline \multirow{2}{*}{$\begin{array}{c}\text { Nominal } \\
\text { diameter } \times \text { wall thickness } \\
(D \times S), \mathrm{mm}\end{array}$} & \multicolumn{2}{|c|}{$\begin{array}{c}\text { Difference of internal diameters of parts } \\
(\Delta d) \text { joined by welding, mm }\end{array}$} \\
\cline { 2 - 4 } & $0.01 D$ & $0.015 D$ & $0.02 D$ \\
\hline $18 \times 2.5$ & 0.18 & 0.27 & 0.36 \\
\hline $38 \times 3.5$ & 0.38 & 0.57 & 0.76 \\
\hline $57 \times 4.0$ & 0.57 & 0.86 & 1.14 \\
\hline
\end{tabular}




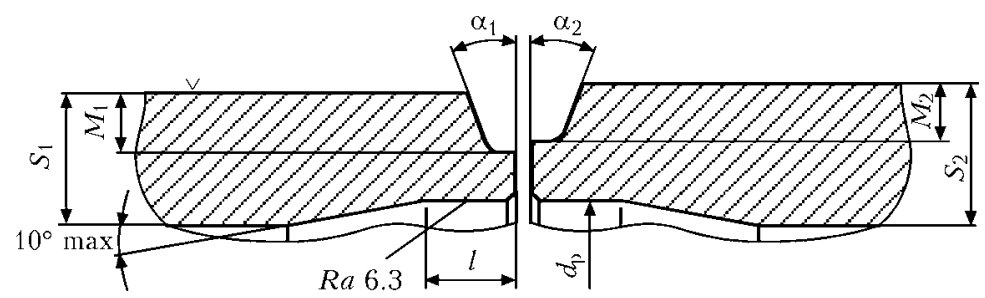

Figure 1. Scheme for edge groove preparation steel 20 of pipe with wall thickness from 5 to 12 mm for simulation of deviations of linear and angular dimensions of parts, subjected to welding, from reference values (conditions of skewness of bevel angles and conditions for joining of pipe parts with different root face) in S-42 type joint performance

Table 3. Linear dimensions of edge grooves preparation in specimens of pipeline parts from steel 20 for simulation of deviations from regulated values

\begin{tabular}{|c|c|c|c|c|c|c|c|}
\hline \multirow{4}{*}{$\begin{array}{c}\text { Pipe nominal } \\
\text { values }(D \times S) \text {, } \\
\text { mm }\end{array}$} & \multicolumn{7}{|c|}{ Edge groove preparation } \\
\hline & \multicolumn{2}{|c|}{ Boring diameter $d_{\mathrm{b}}, \mathrm{mm}$} & \multirow{3}{*}{$\begin{array}{c}\text { Wall thickness } \\
\text { in place of } \\
\text { boring, not less } \\
\text { than }\end{array}$} & \multicolumn{4}{|c|}{ Root face $(S-M)$ at $S_{1}=S_{2}, \mathrm{~mm}$} \\
\hline & \multirow{2}{*}{ Nominal value } & \multirow{2}{*}{$\begin{array}{l}\text { The largest } \\
\text { allowable } \\
\text { deviation }\end{array}$} & & \multirow{2}{*}{$S_{1}-M_{1}$} & \multicolumn{3}{|c|}{$S_{2}=M_{2}$} \\
\hline & & & & & $M_{2}=M_{1}$ & $M_{2}=M_{1}+1$ & $M_{2}=M_{1}+1.5$ \\
\hline $108 \times 5.0$ & 100 & +0.23 & 2.7 & $2.3^{+0.4}$ & $2.3^{+0.4}$ & $3.3^{+0.4}$ & $3.8^{+0.4}$ \\
\hline $159 \times 6.5$ & 149 & +0.26 & 3.8 & $2.7^{+0.3}$ & $2.7^{+0.3}$ & $3.7^{+0.3}$ & $4.2^{+0.3}$ \\
\hline $219 \times 12.0$ & 199 & +0.30 & 8.8 & $3.0^{-0.3}$ & $3.0^{-0.3}$ & $4.0^{-0.3}$ & $4.5^{-0.3}$ \\
\hline
\end{tabular}

Specimens of parts of 18 and $38 \mathrm{~mm}$ diameter pipelines treated in accordance with Tables 1-3 were subjected to automatic non-consumable argon-arc orbital welding (GTAW) by pressure molding method. ADTs 625 U3.1 automatic machine was used for GTAW of position butts of 18-42 mm diameter pipelines. Welding of specimens of parts of $57 \mathrm{~mm}$ diameter pipelines with $4 \mathrm{~mm}$ wall thickness by sequential penetration method was carried out applying ADTs 626 U3.1 automatic machine for GTAW of position butts of 42-76 mm diameter pipelines [10]. Specimens of parts of 108 and $159 \mathrm{~mm}$ nominal diameter pipelines from steel 20 were subjected to multipass GTAW with filler wire feed and oscillations of non-consumable electrode. At that ADTs 628 UKhL4 and ADTs 629 UKhL4 automatic machines were used for GTAW of position butts of 76-108 and 108-159 $\mathrm{mm}$ diameter pipelines, respectively [11]. Specimens of parts of pipelines with $219 \mathrm{~mm}$ diameter were put to multi-pass manual TIG welding with filler wire feed. At that ITs 617 U3.1 power source for TIG welding, power supply module MPS-101, welding current regulator RDG-201 U3.1 [12], ABITIG GRIPP26 torch (ABOCOR BINZEL company) with $3.15 \mathrm{~mm}$ diameter tungsten electrode of WT20 grade and Sv-08G2S $1.6 \mathrm{~mm}$ diameter filler wire were used.

Quality of welded joints in specimens of parts of 18-159 mm diameter pipelines was inspected by visually, radiographic and penetrant methods
[13]. The following is determined based on results of performance of several series of pilot welding:

- when performing S-39 type welded joints of 14-76 mm diameter pipe with wall thickness up to $4 \mathrm{~mm}$, the deviations of plane of the ends subjected to treatment and further welding of parts should not exceed 1.23 angle degree of normal line relatively to longitudinal pipe axis for $18 \times 25$ pipes, 0.55 angle degree for $38 \times 3.5$ pipe, 0.36 angle degree for $57 \times 4.0$ pipe etc. However, in all cases they should be not more than $0.3 \mathrm{~mm}$, since the deviations exceeding this value provide for high possibility of appearance of weld defects such as sagging, lack of penetration, edge lack of fusion, undercuts;

- deviations of internal diameters of parts, subjected to welding, from reference values in welding of S-39 type joints should not exceed $0.01 D_{\text {nom }}$ value, where $D_{\text {nom }}$ is the pipe nominal external diameter. Nonobservance of this requirement result in formation of such defects as violations of weld regulated shape, lack of penetration, edge lack of fusion, root concavities;

- skewness of groove bevel angles of specimens of pipeline parts in performance of S-42 type welded joints should not exceed 4 angle degree. Large values of skewness of bevel angles are characterizes by such solid defects as inadmissible failures in weld formation, lack of fusion of edges and separate beads, lack of penetration in final passes, sagging of weld part close to edge with overstated bevel angle, undercuts in facing weld; 
- deviations of boring of internal diameters from reference values in welding of S-42 type joints should not exceed $+0.23 \mathrm{~mm}$ for $108 \times 5$ pipe, $+0.26 \mathrm{~mm}$ for $159 \times 6.5$ pipe, $+0.3 \mathrm{~mm}$ for $219 \times 12$ pipe, and difference between both root faces should not exceed $0.5 \mathrm{~mm}$, since pipeline part welds, in which root face of one of the edges deviates from root face of another more than per $0.5 \mathrm{~mm}$, tend to such defects of root weld as failure of its regulated shape, lack of penetration, sagging of the weld from one of its side surfaces and concavities or lack of fusion from another. At that the defects of root weld are very rare and in some specimens they are not found at all in the case of application of welding modes with modulated current even at up to $0.75 \mathrm{~mm}$ difference between root face.

Investigations on determination of ranges of cutting optimum modes were also carried out in addition to analysis of the effect on welded joint quality of accuracy of preparation of pipeline part edges for welding. Necessity in such investigationt is caused by peculiarities of corrosionresistant steels of austenite class (for example, 08Kh18N10T grade), relating to base materials, which are used for NPP pipelines, as well as peculiarities of processes of their machining.

One of the main peculiarities of corrosion-resistant steels lies is the fact that their structure represents itself solid solution of austenite class with face-centered cubic lattice [14]. Austenite class steels are the most difficult for machining among the all types. This can be explained by series of factors, main of which is tendency of such steels to cold working, at that even insignificant deformations promote for strong metal hardening. In cutting treatment, high toughness of austenite class steels promotes for formation of long chips that also deteriorates treatment conditions. Low heat conductivity of corrosion-resistant steels stipulates elevated temperature in cutting zone and, as a result, activation of adhesion and diffusion processes as well as intensive bonding of contact surfaces and failure of tool working part.

Experimental and technological works on determination of optimum cutting modes were carried out in specimens of pipeline parts from 08Kh18N10T steel of 18, 38, 57, 108, 159 and $219 \mathrm{~mm}$ nominal diameter and 2.5, 3.5, 4, 5, 6.5 and $12 \mathrm{~mm}$ wall thickness. At that, the recommendations were used determined in the course of many-year investigations directed on machining of austenite class steels and available industrial experience of such treatment [14]. According to these recommendations, the optimum val-
Table 4. Optimum values of parameters of treatment modes for pipeline parts from 08Kh18N10T steel

\begin{tabular}{||l|c|c|c||}
\hline \multirow{2}{*}{\multicolumn{1}{|c|}{ Name of operation }} & $\begin{array}{c}\text { Nominal } \\
\text { dimensions of } \\
\text { pipe }(D \times S), \\
\mathrm{mm}\end{array}$ & $\begin{array}{c}\text { Values of parameters of } \\
\text { cutting modes }\end{array}$ \\
\cline { 3 - 4 } & $\begin{array}{c}\text { Cutting } \\
\text { rate, } \\
\mathrm{m} / \mathrm{min}\end{array}$ & $\begin{array}{c}\text { Feed for } \\
\text { finish } \\
\text { turning, } \\
\mathrm{mm} / \mathrm{rev}\end{array}$ \\
\hline Trimming and cutting & $18 \times 2.5$ & 10 & 0.05 \\
\hline Boring of internal diame- \\
ter & $38 \times 3.5$ & 12 & 0.06 \\
\cline { 2 - 4 } Bevel formation & $57 \times 4.0$ & 15 & 0.07 \\
\hline Root face formation & $108 \times 5.0$ & 10 & 0.08 \\
\hline Internal diameter boring & $219 \times 12.0$ & 20 & 0.10 \\
\hline
\end{tabular}

ues of cutting speed are limited by a range from 10 to $40 \mathrm{~m} / \mathrm{min}$ in the case of fine external longitudinal turning and undercutting of parts from 08Kh18N10T steel. At that, the values of correction factors $K_{m}$ and $K_{n v}$ make 0.8 and 0.9 , respectively. The first one considers the effect of physical-mechanical properties of billet from corrosion-resistant steel on cutting rate, and the second takes into account the effect of surface condition of this billet on cutting rate. The recommended feed rates for precision turning of parts from heat-resistant and stainless steels using cutting tools with hard-alloy plates are from 0.04 to $0.12 \mathrm{~mm} / \mathrm{rev}$.

The results of investigations on determination of ranges of optimum modes for treatment by cutting of pipeline parts from $08 \mathrm{Kh} 18 \mathrm{~N} 10 \mathrm{~T}$ steel showed that the optimum cutting mode values should correspond to that given in Table 4 .

Peculiarities of construction of new equipment for preparation of pipeline position butts for welding. Analysis of information on parameters, characteristics and design of the best foreign examples of equipment for treatment of ends and edges of pipeline parts subjected to welding, for example, produced by PROTEM, POLYSOUDE (France), ARC MACHINES (USA), ESAB, Atlas Copco (Sweden), Georg Fischer, DEPRAG (Germany), ISCAR (Israel), Petersburg Industrial Company (Russia), Aotai (China) [15-23 etc.] companies, showed that these analogues have the following disadvantages:

- mainly internal positioning, which promotes for certain difficulties in performance of mandatory on-line inspection of geometry parameters of pipe ends or edge groove preparation of pipeline position butts and significantly increasing amount and duration of preparatory and finishing operations and, respectively, duration of personal staying in zone of radioactive pollution; 
- absence of some important options, necessary for fulfillment of the requirements of acting in Ukraine PN AE and other normative documents (for example, end facers of foreign production can't provide internal pipe boring);

- high price and significant service expenses.

Therefore, one of the main tasks in development of domestic equipment for machining of ends and edges of pipeline parts subjected to welding was development of models of equipment free from disadvantages typical for foreign analogues, but at the same time close to these analogues by weight.

Earlier carried investigations and production practice showed that achievement of high machining quality of pipe ends and groove edges of pipeline position butts, their assembly and further welding is possible under condition of positioning the mechanisms for treatment, assembly, alignment and welding over the pipe external surface [24]. Such a positioning makes a basis in construction of models of domestic equipment for preparation of pipeline position butts for welding, which are developed at the PWI together with REC WCPE.

Any device for machining of pipe ends or groove edges in pipeline position butts consists of such main parts as driver - electric or pneumatic drive unit, reduction gear, face plate with set on it support (supports), each of which is equipped with one or two tool holders and mechanism of cutting tool feed.

The driver is one of the most important and necessary assembly units of equipment for preparation of pipeline butts for welding. Construction of drivers for this equipment in form of pneumatic drives is seemed to be the most reasonable taking into account designation, peculiarities of such equipment and specific conditions of its operation at NPP.

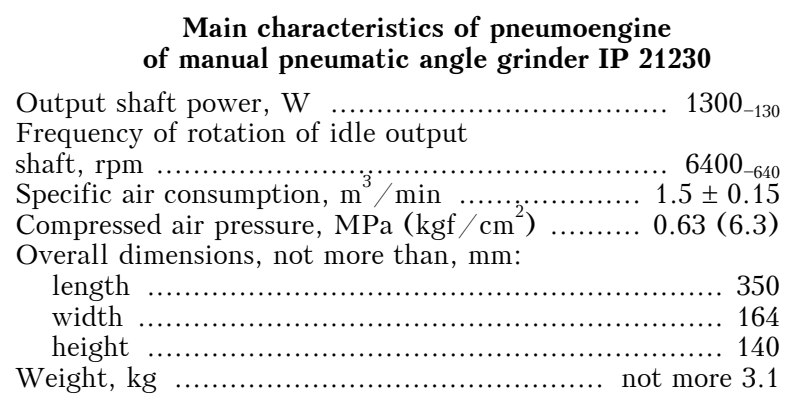

Pneumoengine is a basis of any pneumatic drive unit. The pneumoengines in comparison with drivers of other types have series of advantages, among which are significantly lower specific volume, size and weight than in electric engines with similar energy parameters (power etc.), capability of safe operation under condi- tions of simultaneous effect of high temperature and humidity of environment, significant vibrations and knocks, indices of safety higher than in electric engines, fundamental possibility (in contrast to electric drives) to provide fulfillment of safety requirements in operation under dangerous and particularly dangerous conditions, lot easier and cheaper service maintenance.

Pneumoengines of vane type [25], having the largest widespread, are characterized by the highest safety. Turning moment of the latter is determined by vane surface area, which is subjected to compressed air pressure, and level of this pressure. This provides for the possibility for regulation of rate and turning moment of pneumoengine by means of change of pressure of air coming in it.

Typical peculiarities of vane type pneumoengines are the necessity in providing structural strength and rigidity of cylinder-body and high accuracy of treatment of its internal surfaces. It, from the one side, requires manufacture of body billet by forging or using other technologically complex forming methods and, from the other, obligatory application of not only high-frequency metal-working machines, but special technological fitting and non-standard devices for control of linear and angle dimensions, and fulfillment of the requirements on optimum profile and accuracy of manufacture of rotor vanes, on gaps between vane edges and body internal surfaces, and outlet port size. Indicated peculiarities of pneumoengine manufacture stipulate significant primary expenses for technological equipment and fitting as well as production preparation. It can be economically proved only under conditions of large-series or gross production. It should be also taken into account that there is no domestic production of pneumoengines up to the present moment.

Circumstances mentioned above and tendency to unification of main constituent parts of domestic equipment for machining of ends and edges of pipeline parts subjected to welding are taken into account. So, it is reasonable and economically relevant to use serial pneumoengines of finished models of pneumotools, in particular, imported from CIS countries or South-West Asia, for example, pneumoengine of manual pneumatic angle grinder IP 21230.

Providing real machining modes requires that a face-plate in equipment for preparation for welding of pipeline position butts with imbedded in it cutting tool should rotate at a rate significantly less in comparison with rotation rate of output shaft of pneumoengine. The latter can be achieved only by means of corresponding reduction. This 
promotes for presence of special transmission-reduction gear in structure of equipment for preparation to welding of pipeline position butts.

There are reduction gears of different types, main of which are planetary, helical and worm. In comparison with other reduction gears, the planetary reduction gears are characterized by high efficiency, low inertia moment, capability to reproduction of large reduction ratios as well as the smallest size in relation to turning moment created by reduction gear $[8,26]$.

In addition to this, an important advantage of planetary reduction gear is the possibility of simple flange connection, positioning of reduction gear shaft in the center and free selection of spatial position. Mentioned advantages of planetary reduction gears predetermined selection of double straight-type reduction gear, specifically of this type in construction of domestic models of equipment for welding of pipeline position butts. At that, all developed models of end facers and pipe cutters use not only the same unified pneumodrive, but the same unified variant of planetary reduction gear.

Theoretical basics of designing of machine parts and mechanisms, experience of development and construction of equipment for metal treatment by cutting and taking in account properties of materials, being subjected to treatment in preparation for welding of pipeline parts, conditions of such treatment and requirements to processes of preparation of position butts in NPP pipelines of 14-159 $\mathrm{mm}$ diameter were used as a basis for development of kinematic schemes of pilot specimens of end facers TRTs 38 U3.1 (for pipes of 14-38 mm diameter and wall thickness to $5 \mathrm{~mm}$ ) and TRTs 76 U3.1 (for pipes of 38$76 \mathrm{~mm}$ diameter and wall thickness to $7 \mathrm{~mm}$ ), and pipe cutter TTTs 660 U3.1 (for pipelines of 108-159 mm diameter and wall thickness to $15 \mathrm{~mm}$ ). At that, kinematic and power calculations for transmissions and mechanisms of faceplates of these end facers and pipe cutter, calculation of strength and life of elements of such transmissions and mechanisms as well as calculation of cutting force were carried out. It allowed selecting necessary materials.

Figure 2 shows kinematic scheme of the developed domestic end facers TRTs 38 U3.1 and TRTs 76 U3.1, and Figure 3 gives kinematic scheme of pipe cutter TTTs 660 U3.1.

Investigations and practice show that one of the main factors, limiting the possibility of pipeline part treatment in zones with environment increased aggressivity and allowable duration of production personal staying in such conditions,

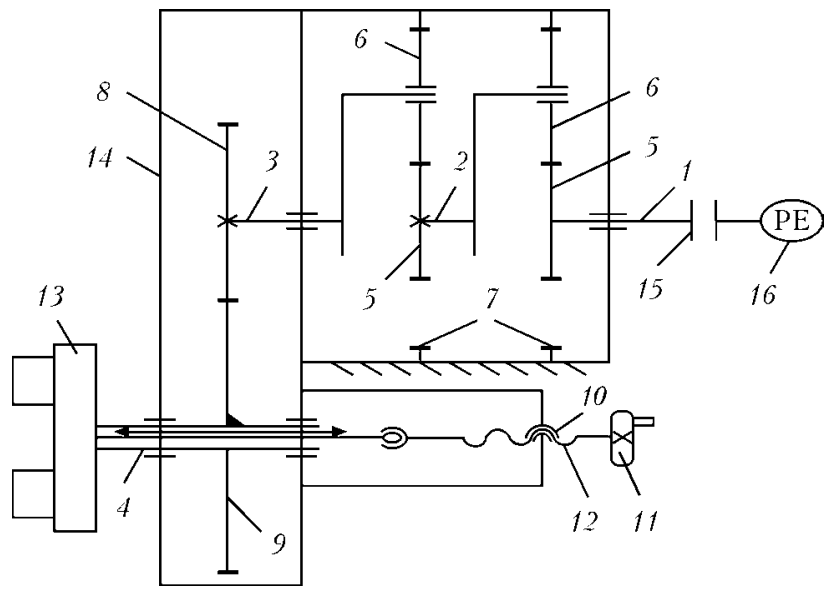

Figure 2. Kinematic scheme of pilot end facers: 1-4 shafts of kinematic segments; 5-9 - gears of kinematic segments; 10 - nut; 11 - handwheel; 12 - feed screw; 13 - face-plate; 14 - body; 15 - socket; 16 - pneumoengine

is a time interval necessary for performance of cutting process itself as well as re-adjustment of cutting tool. Therefore, one of the ways for increase of efficiency of equipment for treatment of NPP pipeline parts lies in such a design of face-plate. It provides for possibility of simultaneous treatment of several surfaces due to presence in its structure of several cutting tool holders that promotes for maximum possible reduction of duration of cutting process and re-adjustment of cutting tool. Based on this, the technical solutions were proposed. According to them two diametrical supports are installed on face-plate of each of end facers that provides for the possibility of simultaneous treatment of pipe ends with

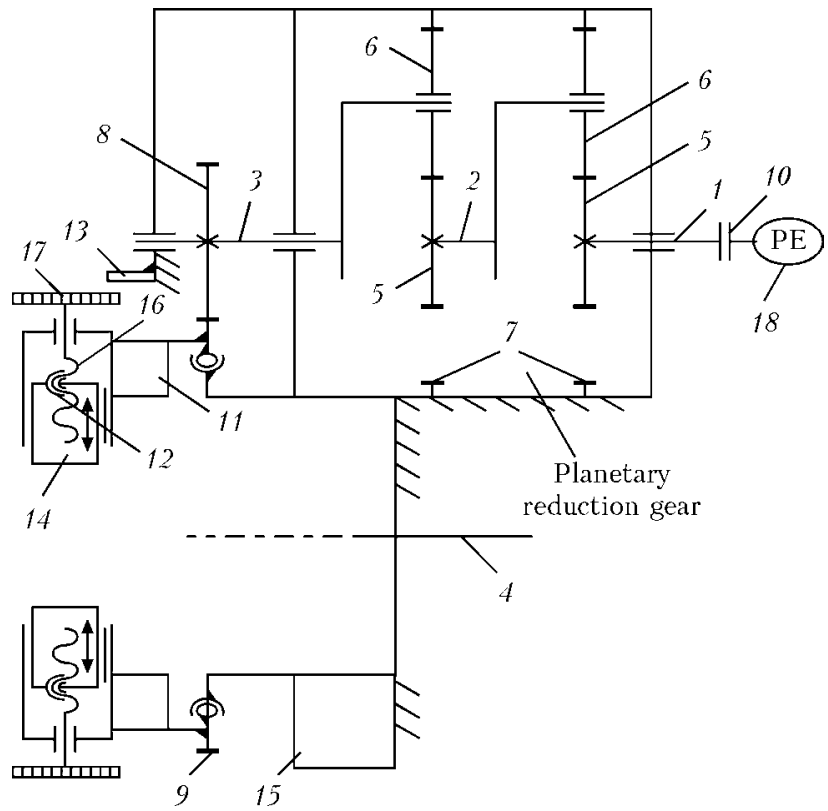

Figure 3. Kinematic scheme of developed pipe cutter: 14 - shafts of kinematic segments; 5-9 - gears of kinematic segments; 10 - socket; 11 - face-plate; 12 - nut; 13 turn lock; 14 - support; 15 - body; 16 - feed screw; 17 - tooth wheel; 18 - pneumoengine 
the help of four cutting tools. At that facing of pipe, formation of external and internal faces and internal pipe boring are carried out simultaneously in one pass.

Similar approaches are typical for designing the structure of split pipe cutter, the face-plate of which is proposed to be made in form of turret head with two transverse supports and one bored. It allows for combining the work of several cutting tools of different configuration, for example, one cutting tool can be fixed in each of two transverse supports, or cutting off tool in one transverse support and straight turning tool in other, besides this cutter can be set for performance of external face. It should also be noted that simultaneous application of two supports with set in it cutting tools allow significantly increasing safety of equipment due to balancing of banding strains, which inevitably appear in process of cutting and having negative effect on kinematic segment elements. The latter consists of output shaft of reduction gear and gear drive from reduction gear to face-plate.

Assemblies of reverse feed of TRTs 38 U3.1 and TRTs 76 U3.1 end facers providing manual feed are made according the same construction diagram. It provides for possibility of movement in any of two possible directions of face-plate of end facers together with cutting tools set in its slides (tool holders) by means of interaction of rod of feed

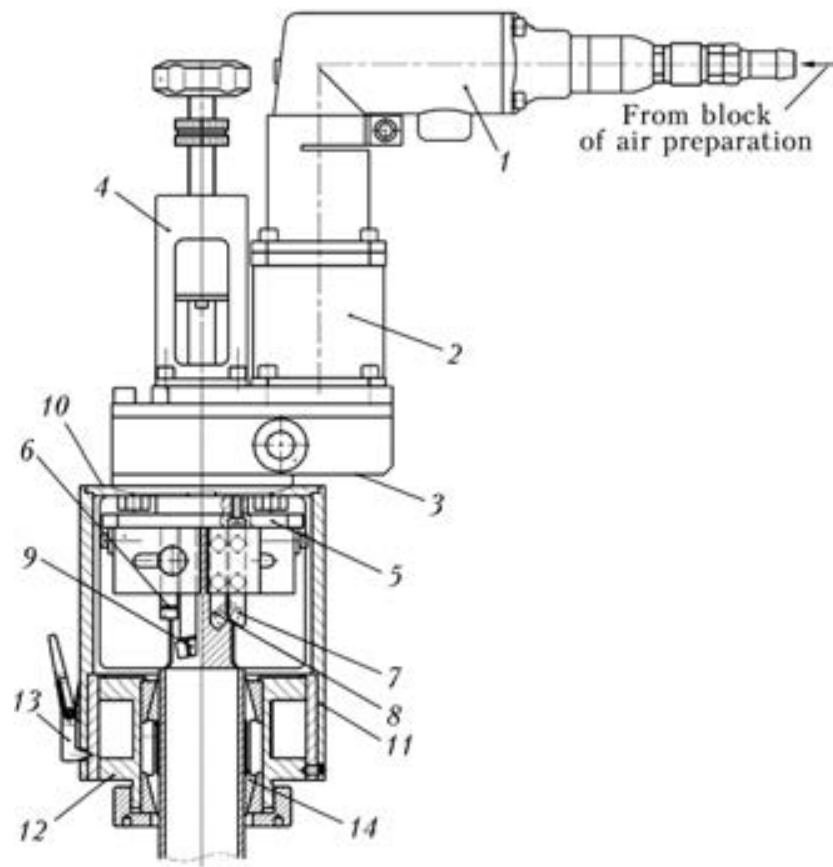

Figure 4. Structural scheme of end facer with self-alignment: 1 - drive unit (pneumoengine); 2 - reduction gear; 3 - stationary body; 4 - feeder; 5 - face-plate; $6-9-$ side-facing and straight turning tools (for formation of inner and outer faces, respectively); 10 - head; 11 - stationary body of head; 12 - positioning mechanism; 13 - fast spring-loaded locks; 14 - self-alignment mechanism assembly with face-plate rod. TTTs 660 U3.1 pipe cutter includes automatic feeding of cutting tools with the help of feed screw, on which tooth wheel of «star» type is installed. After face-plate has made one complete revolution, the tooth wheel moves for one tooth and is fixed in this position with the help of spring-loaded ball. As a result corresponding rotary motion of feed screw takes place, and, based on this, translational motion of the slider with cutting tool set on face-plate per one step of automatic feed. The condition for rotation of «star» type tooth wheel of transverse support per only one tooth from previous fixed position to the next is provided with the help of rotation lock, which is rigidly fixed to one of the stationary pipe cutter bodies.

Carried investigations on peculiarities of processes of preparation for welding of pipeline position butts and industrial experience determined that machining accuracy of pipe ends and groove edges of pipeline position butts, as well as cleanness of treated surfaces, mainly depend on accuracy and reproducibility of alignment of end faces and pipe cutters on treated pipes. Analysis of possible structural solutions in equipment for preparation for welding showed that invariance of initial external positioning of models of this equipment (mainly end facers) is achieved in the case if their structure provides for presence of self-alignment mechanism. Following from this, technical solution ${ }^{*}$ was proposed in process of development of domestic equipment for preparation to welding of pipeline position butts. According to it assembly for treatment of ends and edges consists of stationary head, including mechanism for positioning on pipe external surface, and stationary body with inside face-plate containing tool holders. Due to the presence of (at least two) fast-acting spring-loaded locks, for example of lever type, the stationary positioning mechanism has the possibility of fast connection with stationary body of the head or disconnection from this body. Besides, the head also includes a self-alignment mechanism, for example of collet type, which has rigid connection coaxial with longitudinal axis of treated pipe and longitudinal axis of positioning mechanics. Figure 4 shows the structural scheme of end facer built using proposed solution.

Company CHEZARA (Chernigov, Ukraine), based on technical documents developed by PWI REC WCPE, produced the pilot specimens of

\footnotetext{
*Lobanov L.M., Smolyakov V.K., Vodolazsky V.E., Makhlin N.M. Portable device for treatment of ends and edges of pipes at their preparation for welding. Pat. appl. UA 201503704 of 20.04.2015.
} Int. Cl. B23K 9/235 (2006.01). 
Table 5. Main parameters and characteristics of pilot specimens of end facers and pipe cutter, and their analogues

\begin{tabular}{|c|c|c|c|c|c|}
\hline \multirow[b]{2}{*}{ Parameter or characteristic } & \multicolumn{5}{|c|}{ Model } \\
\hline & TRTs 38 U3.1 & TRTs 76 U3.1 & TTTs $660 \mathrm{U} 3.1$ & $\begin{array}{l}\text { Mangust-2T } \\
\text { (Russia) }\end{array}$ & $\begin{array}{l}\text { PROTEM } \\
\text { PUS40 (France) }\end{array}$ \\
\hline Smallest outer diameter of treated pipe, mm & 14 & 38 & 108 & 45 & 43 \\
\hline Largest outer diameter of treated pipe, $\mathrm{mm}$ & 38 & 76 & 159 & 120 & 219 \\
\hline Largest wall thickness of treated pipe, mm & 5 & 7 & 15 & 5 & 16 \\
\hline $\begin{array}{l}\text { Length of boring of internal diameter of treated } \\
\text { pipe, mm, not less than }\end{array}$ & 10 & 15 & 20 & \multicolumn{2}{|c|}{ No boring option } \\
\hline Positioning & \multicolumn{3}{|c|}{ On pipe outer surface } & \multicolumn{2}{|c|}{ Inner } \\
\hline Method of cutting tool feed & Manual & Manual & Automatic & Manual & Manual \\
\hline Cutting tool feed, $\mathrm{mm} / \mathrm{rev}$, not more than & 0.20 & 0.15 & 0.10 & 0.20 & 0.20 \\
\hline Nominal frequency of face-plate rotation, rpm & 110 & 100 & 60 & 70 & 25 \\
\hline $\begin{array}{l}\text { Consumption of compressed air at idle running, } \\
\mathrm{m}^{3} / \mathrm{min} \text {, not more than }\end{array}$ & 1.5 & 1.5 & 1.5 & 1.7 & 1.6 \\
\hline Overall dimension, $\mathrm{mm}$, not more than & $350 \times 140 \times 170$ & $370 \times 160 \times 175$ & $520 \times 500 \times 435$ & $470 \times 400 \times 120$ & $400 \times 246 \times 246$ \\
\hline Weight with drive unit, kg, not more than & 9.5 & 12.6 & 19.3 & 9.5 & 16.0 \\
\hline
\end{tabular}

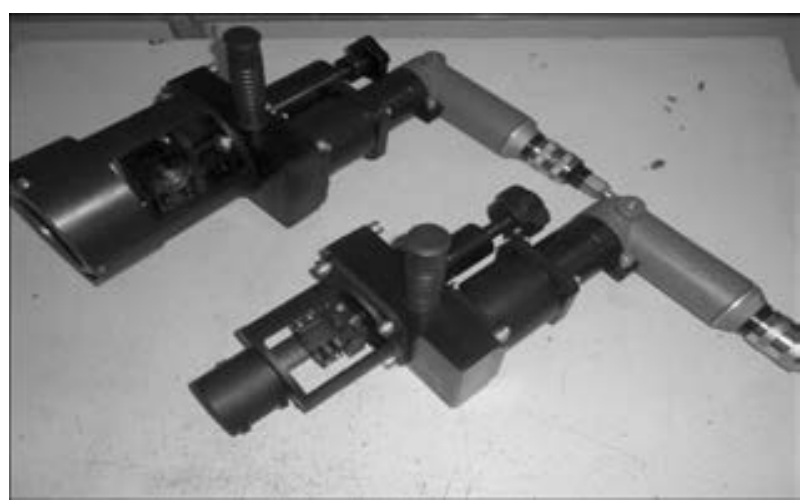

Figure 5. General view of pilot samples of TRTs 38 U3.1 and TRTs $76 \mathrm{U} 3.1$ (on the left) end facers

end facers TRTs 38 U3.1 and TRTs 76 U3.1, and pipe cutter TTTs 660 U3.1, general view of which are given in Figures 5 and 6. Manufactured pilot specimens of equipment for preparation for welding of pipeline position butts were subjected to thorough investigations, including general-theoretical and functional ones. Technological investigations were carried out by REC WCPE together with specialists of «Atomremontservice» of «Energoatom». Table 5 gives the results of investigations carried with pilot specimens of end facers and pipe cutter, their parameters and characteristics.

\section{Conclusions}

1. Considered are the issues of effect on quality of welded joints of accuracy in preparation for welding of edges of parts of position butts in 14-159 $\mathrm{mm}$ diameter NPP pipelines from austenite and pearlite class steels. Ranges of optimum modes for treatment of ends and edges of these pipelines were determined as well as pecu-

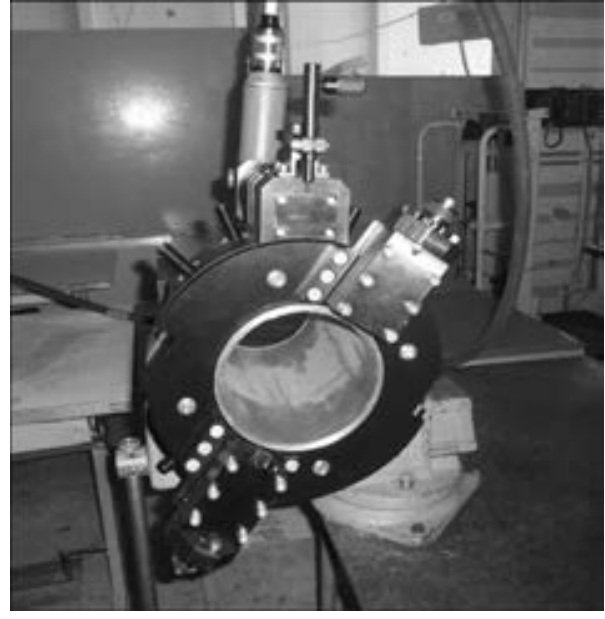

Figure 6. General view of pilot specimen of TTTs 660 U3.1 pipe cutter

liarities of construction of equipment for preparation to welding of pipeline position butts were considered, and pilot specimens of such domestic equipment were manufactured and tested.

2. Results of testing of pilot specimens of end facers TRTs 38 U3.1 and TRTs 76 U3.1 and pipe cutter TTTs 660 U3.1 indicate that in comparison with the best foreign specimens of equipment for preparation to manual or automatic welding of parts of pipe position butts they can provide for:

- expansion of technological capabilities of equipment for preparation to welding of parts of position butts in steel pipelines;

- increase of efficiency of the processes of machining of steel pipeline position butts due to simplification of conditions for testing of internal geometry dimensions of treated pipes;

- simplification and reduction of prices on servicing of equipment for preparation for weld- 
ing of parts of steel pipeline position butts due to maximum possible application in this equipment of domestic spare parts and materials and significant improvement of its repairability;

- not less than 1.5-2 times reduction of prime cost of these products;

- increase of quality and accuracy of preparation for welding, including automated one, of steel pipeline position butts.

Mentioned advantages of developed domestic equipment mainly relate to end facers and are received due to technical solutions concerning their positioning over external surfaces of treated pipes, providing the possibility of simultaneous facing, formation of external and internal faces and boring of inner diameter of these pipes as well as fast connection / disconnection of stationary mechanism for positioning of operating head with its stationary body.

3. Development, manufacture and testing of above-mentioned pilot specimens of end facers and pipe cutter and further mastering of their commercial production create backgrounds necessary for equipping the assembly and repair subdivisions and enterprises from power and other branches by state-of-the-art domestic equipment for preparation for welding of parts of steel pipeline position butts. This provides for elimination of one of the main factors preventing wide-spread implementation of finished as well as novel domestic technologies of automatic welding of pipeline position butts.

1. Cameron, I.R. (1987) Nuclear reactors. Moscow: Energoatomizdat.

2. (1990) $P N A E$ G-7-008-89: Rules of arrangement and safety service of equipment and piping of nuclear power plants. Moscow: Energoatomizdat.

3. (1991) $P N$ AE G-7-009-90, PN AE G-7-010-90: Equipment and piping of nuclear power plants. Welding and surfacing. Fundamentals. Moscow: Energoatomizdat.

4. Roshchin, V.V., Khavanov, V.A., Akulov, L.I. et al. (2002) Welding in mounting of equipment and metal structures of reactor plants. In: Welding in nuclear industry and power engineering: Transact. of NIKIMT, Vol. 1, 81-118. Moscow: IzdatAT.

5. Grinenko, V.I., Roshchin, V.V., Khavanov, V.A. et al. (2008) To problem of automation of welding of mounting joints of nuclear power plant piping. Tekhnologiya Mashinostroeniya, 8, 48-51.

6. Belkin, S.A., Shefel, V.V. (1985) Automatic argonarc welding in mounting of nuclear power plant piping. Energet. Stroitelstvo, 11, 43-46.

7. Bukarov, V.A. (2002) Technology of automatic arc shielded-gas welding. In: Welding in nuclear industry and power engineering: Transact. of NIKIMT, Vol. 1, 149-210. Moscow: IzdatAT.

8. Volkov, V.A. (2000) Special cutting equipment. Tekhnologiya Mashinostroeniya, 5, 6-10.

9. Troitsky, V.A. (2012) Visual and measuring control of metal structures and constructions. Kiev: Feniks.

10. Makhlin, N.M., Korotynsky, A.E., Bogdanovsky, V.A. et al. (2011) Single- and multioperator systems for automatic welding of position butt joints of nuclear power plant piping. The Paton Welding J., 11, $28-36$.

11. Makhlin, N.M., Korotynsky, O.E., Svyrydenko, A.O. (2013) Hardware and software complex for automatic welding of position butts of nuclear power plant piping. Nauka ta Innovatsii, 9(6), 31-45.

12. Makhlin, N.M., Korotynsky, A.E., Bogdanovsky, V.A. et al. (2004) Electronic controllers of welding current for multioperator welding systems. Svarochn. Proizvodstvo, 5, 13-18.

13. Troitsky, V.A. (2006) Compendium on quality control of welded joints. Kiev: Feniks.

14. Reference book of technologist-mechanician, Vol. 2. Ed. by A.M. Dalsky et al. Moscow: Mashinostroenie-1.

15. http://www.protem.fr

16. http://www.polysoude.com/

17. http://www.arcmachines.com

18. http: / www.esab.com

19. http:// www.atlascopco.com

20. http://www.georgfischer.com

21. http:// www.deprag.com

22. http:// www.iscar.com

23. http: / / www.pkfppk.ru

24. Belousov, A.N., Chernyshov, G.G. (1977) Some problems of pipe butts preparation to welding. Svarochn. Proizvodstvo, 4, 39-41.

25. http://www.immerservice.ru/privod/pnevmodvig ateli/

26. Chernavsky, S.A., Snesarev, G.A., Kozintsev, B.S. et al. (1984) Design of mechanical transmissions: Manual for high technical schools. Moscow: Mashinostroenie.

Received 18.06.2015 